\title{
Rubidium isotope fractionation during chemical weathering of granite is driven by minerals transformation
}

ZHUO-YING ZHANG ${ }^{12}$, JIN-LONG MA ${ }^{1 *}$, ZHI-BING WANG $^{1}$, LE ZHANG ${ }^{1}$, XIN-YUE HE ${ }^{12}$, GUAN-HonG $\mathrm{ZHU}^{12}$, TI ZENG ${ }^{3}$, GANG-JIAN WEI ${ }^{1}$

${ }^{1}$ State Key Laboratory of Isotope Geochemistry, Guangzhou Institute of Geochemistry, Chinese Academy of Sciences, Guangzhou, 510640, China (*correspondence:

jlma@gig.ac.cn; zhangzhuoying@gig.ac.cn; wangzhibing@gig.ac.cn; zhangle@gig.ac.cn; hexinyue@gig.an.cn; zhuguanhong@gig.ac.cn; gjwei@gig.ac.cn)

${ }^{2}$ College of Earth and Planetary Sciences, University of Chinese Academy of Sciences, Beijing 100049, China

${ }^{3}$ CAS Key Laboratory of Marginal Sea Geology, Guangzhou Institute of Geochemistry, Chinese Academy of Sciences, Guangzhou 510640, China (zengti@gig.ac.cn)

Rubidium is a moderately volatile, lithophile, fluidmobile element and therefore has been widely used to solve geological problems. However, whether and how its isotopes fractionate during geological processes are poorly known yet. To this end, we measured the $\delta^{87} \mathrm{Rb}$ values of both bulk samples and individual minerals of a granite weathering profile in Guangdong Province, South China, to investigate $\mathrm{Rb}$ isotope fractionation during chemical weathering. Large fractionation of $\mathrm{Rb}$ isotopes in the bulk samples was observed, with $\delta^{87} \mathrm{Rb}$ changing from $-0.30 \pm 0.13 \%$ in the unaltered bedrock to $0.04 \pm 0.08 \%$ o for highly weathered saprolites, suggesting that intensive chemical weathering will make the $\delta^{87} \mathrm{Rb}$ of saprolites heavier. During slightly-moderately weathered stage $(29.0-16.0 \mathrm{~m}), \mathrm{Rb}$ was released by decomposition of primary minerals and partially adsorbed by illite. These processes lead to the ${ }^{87} \mathrm{Rb}$ enrichment in saprolites compared to bedrocks. In highly weathered stage (16.0-3.0 m), the bulk $\delta^{87} \mathrm{Rb}$ values were controlled by the decomposition of $\mathrm{K}$-feldspar and adsorption by illite and kaolinite. Illite and kaolinite in this section not only adsorb the $\mathrm{Rb}$ released from K-feldspar decomposition, but also adsorb those transported from the top section $(3 \cdot 0-0.0 \mathrm{~m})$. Illite prefers to adsorb the ${ }^{85} \mathrm{Rb}$ from vertical migration while kaolinite prefers ${ }^{87} \mathrm{Rb}$. The fractionation of $\mathrm{Rb}$ isotope during chemical weathering was for the first time presented in this study. Our results demonstrated that mineral transformation from primary minerals into secondary ones is the key to controlling $\mathrm{Rb}$ isotope fractionation, which advances our understanding of $\mathrm{Rb}$ behavior. 